\title{
Value Oscillation in Knowledge Infrastructure: Observing its Dynamic in Japan's Drug Discovery Pipeline
}

\author{
Masato Fukushima \\ The School of Arts and Sciences, The University of Tokyo, Japan / maxiomjp@yahoo.co.jp
}

\begin{abstract}
This paper analyses the dynamics of assigned values in two cases relating to the knowledge infrastructure of the national programme in Japan that develops drug discovery: in establishing a database of natural product compounds and in constructing a library of virtual compounds. The concepts of value oscillation and of the M-B (Marx-Bowker) index are proposed to designate the fluctuating appreciation of infrastructure value by its builders. These concepts combine insights from classical Marxist thought on the infrastructure/superstructure distinction (neglected in recent studies on infrastructure in STS) and Bowker's infrastructural inversion. Though value oscillation is almost ubiquitous in the development of any infrastructure, in the cases considered here, it takes peculiar forms because of the complex interaction of the material and knowledge infrastructures. It is widely distributed in the sub-layers that support the autonomy of these knowledge infrastructures and is a precondition for knowledge infrastructures to function as delineated entities.
\end{abstract}

Keywords: value, infrastructure, drug discovery, oscillation, structure

\section{Introduction}

Concepts are the ways through which we see the world, and scholars have long realized that apparent conceptual lucidity may hide winding paths that can produce a variety of contradictory nuances, leading to persisting controversies. Thus, academics from various fields have traced the meandering former paths - including their etymology - of such concepts as subject/object (Williams, 1976), liberalism (Hayek, 1982), society (Luhmann, 1980), and even 'thing' (Heidegger, 1968; Latour, 2005; cf. Fukushima, 2005).

From this perspective, the recent rise of so-called 'infrastructure studies' in STS apparently falls short of reflecting infrastructure's conceptual genealogy, while there are numerous concrete examples analysing what infrastructures are and have been. A brief review of foundational works indicates that infrastructure is usually conceived as a collection of such conventional prototypes as roads, water conduits, and electricity; later, infrastructure took on new, extended meaning in terms of such phenomena as communication, information, and even knowledge (Star \& Ruhleder, 1996; Star \& Bowker, 2002; Edwards et al., 2007; Bowker et al., 2010). This approach to defining the subject, however, is plagued with historical amnesia in 
terms of its intellectual genealogy. The concept of historical amnesia, which will become clearer through the rest of this article, can briefly be defined as blocking recourse to the proper legacy of the past for systematic reasons, often organizational, political, or even social (cf. Bowker \& Star, 1999, ch. 8), in STS scholarship.

By way of demonstration, in 1978, Current Anthropology published an article by Maurice Godelier and colleagues titled 'Infrastructures, Societies, and History' (Godelier et al., 1978). Godelier is well known for his innovative endeavours to unify Marxist anthropology and French structuralism (cf. Godelier, 2011). His paper was intended to redefine the Marxist version of infrastructure to solve the evident contradiction between societies in which such elements as kinship or religious institutions seem to dominate contra Marxists' classical tenet that modes of production determine other societal factors. At stake here is the assumption of historical materialism - namely, that the base, or 'infrastructure', of a given society is defined as the productive forces and social relations of production that unilaterally determine the rest of society, the superstructure (henceforth capitalized to represent their unitary character; Marx, 1973). Large amounts of energy have been expended to improve or even alter this rather rigid framework (Lichtheim, 1971; Howard \& Klare, 1972; McLellan, 1979), and Godelier and colleagues radically expanded the Marxist understanding of Infrastructure to what he calls idéel reality, a notion inspired both by phenomenology and structuralism, consisting of thought and language, knowledge of nature and tool usage, and taxonomy and classification (Godelier et al., 1978: 764).

The concept of Infrastructure has been important since Marx (1973) formulated it in his Grundrisse', and it has underpinned the social sciences to various extents. However, the canonical collections of infrastructure studies noted above seem to be silent about this specific line of Marx's intellectual legacy (cf. Carse, 2012: 542-44). The reason for this amnesia may be that, aside from the fact that the term 'base' is more often used in Marxist terminology, the preferred theoretical approaches of these authors of foundational studies, such as symbolic interactionism
(Star \& Ruhleder, 1996; Star, 1999), system theory a la Parsons and von Bertalanffy (Hughes, 1983), and ANT/SCOT (others), have drawn researchers away from this tradition. In fact, the merit of these approaches is undeniable: by 'clearing and erasing' the past traces (Bowker \& Star, 1999: 257), STS has produced a fairly large number of empirical, finetuned studies of more specific technical infrastructures.

While admitting the advantages, I claim that at least three major problems have been overlooked by not critically conversing about and confronting the Marxist legacy: 1) What is Infrastructure? 2) How does it work? 3) How do we understand it?

1) In STS, the question of what infrastructure is usually relies on Star and Ruhleder's (1996) foundational definition, which presents eight features that are seemingly distinct from the Marxist concern with the mode of material production as the unitary basis for Infrastructure. Overlooked here is not so much the chance of comparing the two as a missed opportunity to refer to the extremely rich inventory of efforts to revise the latter after its initial formulation in Grundrisse. In addition to the ensuing attention to the pivotal influence of the Superstructure on its counterpart (McLellan, 1979; Anderson, 1976), to be discussed below, efforts have also made to find alternatives to modes of production, such as consumption (Bataille, 1988; Baudrillard, 1981) or exchange (Karatani, 2014; cf. Polanyi, 1944; Sahlins, 1972). Among these, the most striking case is the abovementioned innovation of Godelier and others in adding structuralistic elements like taxonomy and classification into Infrastructure, directly leading to Bowker and Star's (1999) similar claim 20 years later, a foundational case for the present treatment of knowledge infrastructure. By failing to examine such preceding efforts, STS researchers have clearly missed the chance of incorporating certain insights into, for example, how the idéel system works together with a more classic mode of production, which could provide clues on the link between the knowledge infrastructure and the wider economy in the present argument ${ }^{2}$.

2) The way Infrastructure works is tightly related to its counterpart, Superstructure; for Marx, his followers, and his critics, however, the relation between these two poles has been the 
target of extensive examination and polemics because critics regard the Marxist definition of Superstructure as too loose, as it includes virtually everything except modes of production. In contrast, STS circles seem to have shown relatively ambiguous attitudes to questions concerning the effect of infrastructure and how it is constructed. Again, the point here is not to adopt the unilateral determination of the earlier formulation, but to re-examine ensuing efforts to reformulate the very meaning of determination: for instance, some even argue that Althusser and Balibar's (1970) concept of overdetermination is essentially in line with the notion of complexity (Shiozawa, 2002), possibly contributing to the present discussion of how multiple infrastructures interact with each other (cf. Vertesi, 2014).

This determination thesis is also directly related to the problem of power in terms of the class that dominates Infrastructure. This element, as part of the legitimate vocabulary of political sociology, seems to have some shadowy resonance in contemporary infrastructure studies; however, references to the issue are both hesitant and lacking theoretical cultivation in terms of what kind of power is related to the issue (cf. Edwards et al., 2007: 24-31; Edwards et al., 2009: 371).

3) The question of the understanding of Infrastructure and the value directly attached to such an act of recognition, the central theme of this article, requires full exploration. In the Marxist conceptualisation of these paired concepts, the latter represents the surface and visible values that apparently dominate society, whereas the former is submerged. The Marxist strategy of historical materialism, in essence, is to destroy this naive view of the dominance of such surface values by 'turning Hegel on his head' (Marx, 1976/81), an act of inversion in the face of the ladder of values that exists both in Hegelian idealism and in the real world, highlighting this apparent inferiority of the value of Infrastructure in order to reveal its determinant power.

Thus formulated, the following arguments concerning infrastructure in STS have followed a similar path without attending to its intellectual ancestry. References to the negative evaluation of infrastructure have been scattered in the preceding body of research, in which infrastruc- ture is described as boring and unexciting (Star, 1999: 377), as maintained by undervalued and invisible workers (Star \& Bowker, 2002; Bowker et al., 2010: 98), and as often characterized by 'tension' with regard to its value (Edwards et al., 2013: 26) ${ }^{3}$. One description of the ambivalent aspect of treating taxonomy as infrastructure summarizes the issue here:
"Being treated as infrastructure has hitherto been a dubious honour. While being considered essential gives one a certain amount of leverage, it also means one risks being taken for granted and neglected in the face of other, more prominent topics." (Hine, 2008)

When this idea is extended to metadata, things do not seem to be radically different:

"All recognize metadata's potential value, but when the rubber meets the road, an unfunded mandate to be altruistic [...] does not prove highly attractive." (Edwards et al., 2012)

Thus, although the conflict of values regarding infrastructure has been a matter of constant, if sporadic, concern even within the study of infrastructure in STS, its formulation lacks the consistency of the Marxist tradition in dealing with their own version of Infrastructure.

\section{Value Oscillation and the M-B (Marx-Bowker) Index}

In this article, drawing upon the last point above, I focus on this discrepancy: whereas the power of infrastructure is recognized, the practices related to it, such as service to others and its maintenance and repair, are not highly ranked in the existing value system, being often regarded as invisible and even 'boring'. Because of this particular nature of infrastructure, Bowker (1994) proposed 'infrastructural inversion', a strategic analytical operation to bring hidden infrastructure to the surface and expose its importance. My claim in this paper is that this particular operation is, in essence, structurally isomorphic with the Marxist operation of 'turning Hegel on his head', different only in terms of its focus and scope of theorization. 
These operations have thus far been confined to analysts' strategies, whereas my examination relates to how practitioners in situ regard the value of infrastructure and its related practices. Conflict, contradiction, and oscillation (as is evident to some extent in the preceding monographs on the issue) are expected from this approach, precisely because practitioners are the ones who develop and maintain infrastructures. Hence, I will adopt the term 'value oscillation' for describing this aspect of fluctuating attitudes, between these two poles of the recognition of its supportive value and avoidance of its shadowy character.

This observation relates intrinsically to the very concept of infrastructure itself, which is almost oxymoronic: though infrastructure exerts immense power as it structures other things, it is inferior (inferus, inferior from infra, in Latin) because it lacks surface value. By way of analogy, Weick and Westley (1999) have claimed that 'organisational learning' is an oxymoron because organizing is a process of reducing complexity, whereas learning increases it; hence, organisational learning is rare. Infrastructure as oxymoron exists rather steadily but generates a double-bind (Bateson, 1972) for its concerned practitioners, owing to its intrinsically opposing vectors of value. Because its value oscillates between these two poles, like other double-bind situations, it is hung in indeterminacy. Hence, my term, 'value oscillation', is more adequate than conventional expressions like 'value conflict' or 'contradiction': these are both too macroscopic, and they also easily connote a 'dialectical' solution of cancelling the contradiction out (aufheben!), which, I believe, rarely happens in a double-bind.

To describe this zig-zag movement of indeterminacy, I introduce a second term, the 'M-B (Marx-Bowker) index', to show the degree of appreciation for the invisible infrastructure values. Here, 'infrastructure' is defined not only as the material entity designated by the term, but also the wider assemblage of activities involving quasipublic services to others, works of a sub-contractive nature, and backstage efforts including those indirectly related to infrastructure building. The juxtaposition of these two names signifies the intrinsic continuity of the two approaches in terms of inverting the underlying value, while simulta- neously emphasising the practitioners' view and action; in addition, the index becomes an easily visualized means for observing the oscillating attitude of the concerned practitioners.

Presupposing practitioners' recognition of the validity of any given infrastructure, the M-B index is defined as concerned practitioners' observed degree of commitment to developing and maintaining a given infrastructure: hence, a high index means a high degree of commitment to it, and a low index implies avoidance of such commitment. In this paper, this index is used as a figurative tool for visualising the observed oscillation of practitioners' attitudes as demonstrated by both their discourse and their actions vis-à-vis the issue of building and maintaining infrastructure. One may argue that such values behind our actions are too complex to be adequately identified with this index. This argument admittedly has some truth; however, I claim that when we focus sharply and directly on the issue of building and maintaining infrastructure, we may reduce it to a simple question of whether one promotes it or avoids it, though there may be intermediate choices with accompanying complementary reasons. Such focused action and discourse, along with any oscillation, are in fact observable, reaffirming Geertz's (1973) classical formulation of cultural practice as a public vehicle of meaning.

My own research is based upon ethnographic observation, and I use such relative expressions as 'high' and 'low' with regard to the M-B index. However, my approach does not preclude the possibility of substantiating the claims by using questionnaires, though I did not attempt such in this project. In such a case, the M-B index could be tentatively quantified, with zero meaning the practitioners' avoidance of any commitment to infrastructure building, and 5 or 10 showing full commitment to its construction, thus expressing a continuum.

Some laboratory studies seemingly present cases of apparent value oscillation concerning the ambivalent role of research tools and related work practices (Clark \& Fujimura, 1996; Gaudilliere \& Löwy, 1998; Joerges \& Shinn, 2001; Mody, 2011), the interchangeability of epistemic things and research technology (Rheinberger, 1997; Joerges \& Shinn, 2001), and the problem of the 
fluctuating status of such tools in the hierarchy of credibility in laboratory settings (Clark \& Fujimura 1992: 16) ${ }^{4}$. However, infrastructure goes far beyond the limited scopes of laboratory and disciplinary boundaries, and its multi-layered character increases the complexity of analysing value oscillation, as it is distributed across diverse spaces and various layers. It is further complicated when extended to its knowledge aspect, wherein 'infrastructure' generally signifies the whole set of heterogeneous elements of databases, computerization, grid systems, e-science, and so on without (thus far) a proper definition (Edwards et al., 2009; Edwards et al., 2013).

In fact, the question of how value oscillation takes shape arises in light of the ongoing momentum and extensive influence of computers, information, and even data science as 'science' (Hine, 2006b, 2008; Edwards et al., 2007; Edwards et al., 2009; Bowker et al., 2010; Edwards et al., 2013). We can presume that these factors push the M-B index both upwards - because the halo of new science attracts devotion - and downwards because 'infrastructuralization' is avoided in such areas compared to established engineering efforts to maintain roads, water, and electricity. Thus, possible strategies that concern the dynamics of knowledge infrastructure become a question of concern.

\section{The Research Subject}

The remainder of this article will discuss 'value oscillation' as it relates to the knowledge infrastructure in two distinct case studies, both related to attempts to build a sort of database as part of the larger scheme of Japan's national policy of developing an infrastructure for drug discovery (sôyaku-kiban) that is academia-based. First, we look at a faltering endeavour to establish a database of natural product compounds to make the search for drug seeds more effective and to facilitate basic research for ligand-protein interaction. Second, we will examine the ongoing construction of a large-scale virtual library of chemical compounds, using a world-class supercomputer.

The analytical focus in these case studies is twofold. The first is on how value oscillation is observable in the multi-layered infrastructures wherein these databases are embedded. The schemes for building such drug discovery infrastructure require coordinating and constructing various layers of sub-infrastructures simultaneously, providing intriguing examples of how the problem of value oscillation is approached in the different layers beyond the confines of the specific databases that are the main focus.

The second focus is how this issue is related to the context of knowledge and material interaction. As drugs are material entities that require a vast amount of heterogeneous knowledge, the development of the knowledge infrastructure in this context is closely related with its material counterpart in producing drugs. By highlighting these two aspects, this paper examines the various appearances of value oscillations throughout the complex, multi-layered character of the knowledge infrastructure and how the practitioners deal with the situation in each contextual effort, along with the consequences ${ }^{5}$.

\section{Background: Drug Discovery Infrastructure as Knowledge Infrastructure}

Drug discovery is a hugely complex process that demands a vast amount of heterogeneous knowledge and related infrastructure, beginning with finding the proper target proteins and drug seeds and progressing to a range of steps from animal testing to clinical trials, which include Phases I to III (Epstein, 2007; Petryna, 2009; Keating \& Cambrosio, 2003, 2012). Behind the policy idea of developing a national drug discovery infrastructure lies the fact that the productivity of drug discovery has decreased sharply despite the growing knowledge and technology related to the process, and controversies have occurred about its possible causes (Epstein, 2006; Ryzewski, 2008; Bartafai \& Lees, 2006; Kubinyi, 2003). Drug companies have thus urged governments to promote the idea of outsourcing such development to academia, which is supposed to be able to bear greater risks. This idea gained momentum when the National Institutes of Health (NIH) in the United States published their Roadmap Initiative for Biomedical Research in 2003 to promote constructing an academic drug discovery infrastructure in the form 
of public chemical libraries and screening centres for academic use (Wikstrom, 2007; cf. Mazzucato, 2013). In response, the Japanese government launched their version of the policy (Fukushima, 2015).

Here, I comment briefly on the peculiarities of considering the drug discovery infrastructure as a particular type of (knowledge) infrastructure. Despite the general usage of the term kiban in policy discourse, 'infrastructure' here means the very specific purpose of producing drugs, as opposed to more general infrastructures like roads and the Internet. The alternative term, the drug discovery 'pipeline', also connotes the horizontal integration of the temporal procedures from bench to bedside. Thus, some researchers prefer using terms like 'platform' (Keating \& Cambrosio, 2003) to highlight the horizontal assemblage of knowledge and material rather than the term 'infrastructure'.

Nevertheless, the term 'drug discovery infrastructure' has its own legitimacy. First, this process consists of multi-layered entities, ranging from the national plan to specific institutions to the laboratory level, where various aspects of infrastructure-like characteristics can be spotted, exhibiting similarity with other types of more conventional infrastructures, such as databases open to academic purposes (Star \& Ruhleder, 1996; Edwards et al., 2007; Edwards et al., 2013).

Second, the process includes a unique entanglement of materiality and knowledge. Although drugs are an industrial material, they are also what Barry (2005, borrowing from Bensaude-Vencent \& Stengers, 1996) calls 'informed material', which requires a huge complex of knowledge from protein science, chemistry, and medicine, wherein the elements of the knowledge infrastructure play pivotal roles.

In the following sections, the sub-institution levels are given priority for the detailed analysis, but higher levels are by no means unrelated. The focal institution is RIKEN, a public research institute representative of basic science in Japan. RIKEN's involvement in the infrastructure plan is the main background. RIKEN has experienced a series of ups and downs, from its pre-war status as the pivotal nexus of research and industry to post-war decline and revival in recent years in the form of national genomic and postgenomic research projects given by its supervising ministry (RIKEN, 2005). After a series of major science projects, such as Protein 3000 Project (Fukushima, 2016), RIKEN launched a plan to establish a more tightly woven infrastructure for drug discovery with a more effective organization of its branches, which had not previously been tightly combined with one another. The following cases both fall within the larger scheme of RIKEN's policy ${ }^{6}$.

\section{The Chemical Biology Centre as Future Quasi-Infrastructure}

The first major topic of this paper is the faltering effort to establish NPEdia (whose name is abridged from 'Natural Products Encyclopaedia'), a database for public use. This project was implemented along with the development of NPDepo, a public library of natural product compounds. These plans were launched in parallel with a government plan to establish a national library of chemical compounds open to academic use. Natural products are the chemical entities produced by living things, such as microbes, plants, and marine organisms. These entities have bioactivity-namely, the effects exerted on other living things. This genre of research has had extensive relations with drug discovery, most notably in the case of antibiotics extracted from fungus, such as penicillin, or recent searches for plants and marine organisms to provide new seeds for drugs (Fukushima, 2015).

This specific idea was promoted by a number of RIKEN's leading laboratories; among them, the antibiotic laboratory (of more than 60 members), which boasts a long genealogy of preceding laboratories in the same genre of research (Ueno, 2008), has taken the pivotal role. This infrastructural innovation was accompanied by an organizational plan to establish a new centre for an emerging hybrid science called 'chemical biology', wherein chemical compounds are used to regulate and probe the activity of life phenomena. In the United States, the above-mentioned Roadmap Initiative policy to promote chemical biology includes a public chemical library and screening centre (Wikstrom, 2007); however, controversies have developed between the $\mathrm{NIH}$ and leading 
scientists there over how best to orient chemical biology for drug discovery (Fukushima, 2013).

Like Matryoshka (Russian nesting) dolls, the problem of value oscillation vis-à-vis the development of various layers of infrastructure can be observed on various levels, from RIKEN itself down to the laboratory practices. One of the focuses here is the centre level, within which the NPEdia/ NPDepo complex is situated. The chemical biology centre plan was once intended to establish one of the hubs for the coming drug discovery infrastructure, both within and without RIKEN, symbolising RIKEN's commitment to connect academia and industry by implementing governmental biomedical policy more directly. For that purpose, RIKEN has increased the number of time-limit centres to improve the infrastructural functioning of various kinds of large facilities, libraries, and databases (RIKEN, 2005). The chemical biology centre, under the leadership of the antibiotic laboratory mentioned above, was once part of this long-term plan. The centre was intended to be equipped with not only the database and library, but also with various assay systems as well as high-throughput machinery to enable the rapid examination of ligand-protein interactions, for public service as well as for their own research. However, a contradiction has thus been revealed about what the centre was meant to be from the beginning.

First, despite the official emphasis on the infrastructural objective, the promoters of this plan also intended to use the centre to pursue their own research innovation. I observed this divided intention during my visit to the laboratory, where a large part of the researchers' energy was spent preparing for the coming centre. In fact, the main members of the laboratory were subdivided into a number of teams, each consisting of a team leader and several members and technicians, each tasked with various infrastructural obligations, such as improving the high-throughput machinery, establishing new assay systems, and collecting and classifying materials for NPEdia/NPDepo.

Here, the division of labour is not confined to scientist/technician distinctions; almost all the scientists were also assigned to one or more infrastructure-related tasks for the coming centre. However, the distribution of such workloads was uneven, with some teams doing basic work like collecting materials and organizing information, while others were only doing their own homework?.

Many examples of value oscillation occurred in this complex distributions of workloads. For instance, the 2008 intra-RIKEN official report, which is issued every seven years about the activity of the laboratory, was concerned mainly with the activities directly related to the infrastructural aspects of the future centre, while the outcomes of the individual research activities were given only passing references. Thus, its $M-B$ index for emphasis on infrastructure elements was high. However, these individual papers were published in major journals and reported in a separate annual record about the laboratory's academic activity (interview, 24/6/2008). In addition, the uneven distribution of the infrastructural workloads led to some rather cutting remarks by some of the staff about their colleagues' work. For instance, after the official interview, one of the team leaders suggested to me that there would be no need to interview some of them, as their work was nothing but technicians' work, not that done by scientists. Such remarks clearly demonstrate a contrastively low M-B index score despite the laboratory's general policy (field note, 20/11/ 2007).

The changing discourse of the laboratory head was a living example of such value oscillation. In a meeting with the whole laboratory, for instance, he rather openly warned those who were then too keen to do service work for outsiders about their infrastructural duties, such as examining the bioactivity of the compounds entrusted to them. Even though these are the sort of preliminary duties that the future centre would be expected to carry out, he underlined the possible danger of doing too much service work for outsiders, which could decrease the quality of their own scientific activity (field note, 15/4/2008). On another occasion, he suggested that the staff collaborate on their entrusted work if they found the job interesting enough to do as part of their own research (field note, 13/11/ 2007). This impressive degree of ambivalence was observed throughout the laboratory, even, as demonstrated, with the 
same leader, with the M-B index score seeming to change daily, like stock prices.

\section{NPEdia and NPDepo: Between Material and Knowledge Infrastructure}

The above example, wherein the whole laboratory was related to the centre plan, rather simply demonstrates the problem of value oscillation. NPEdia and NPDepo, however, present a more subtle picture of how value oscillation is embedded in the more complex layers of multiple infrastructures. To understand this, we must take a closer look at the very concept of both databases as the public library of 'natural product' compounds. As I have shown, this project is officially in line with the wider national science policy programme to establish a public library of chemical compounds, but the uniqueness of this plan lies in its adherence to collecting natural products as opposed to collecting ordinary chemical compounds, as directed in the competing scheme of RIKEN's rival, the University of Tokyo (Fukushima, 2013) ${ }^{8}$.

The idea behind this project derives first from the historical fact that natural products have been powerful sources of drug seeds, especially in microbial cases, which have included a variety of powerful discoveries, from penicillin to statins (Newman \& Cragg, 2007; Endo, 2006). Second, the relatively strong tradition of Japanese research in this area, to which the antibiotic laboratory belongs, led the promoters to maximize their traditional advantages. Third, the unique chemical structures of these natural products were expected not only to promote the search for drug seeds, but also to lead to the development of unique bio-probes for basic biological research (Fukushima, 2015).

NPEdia was designed to supplement the collection of materials, to serve as a legitimate knowledge infrastructure in the wider context of the drug discovery infrastructure, and to function as an encyclopaedia for natural product compounds with annotated meta-information, such as bioactivity and the details of related assay methods. It was also meant to serve as a catalogue for NPDepo to give details on the further uses of the actual compounds that NPDepo provides
Thus, the NPDepo/NPEdia complex was considered pivotal for the coming chemical biology centre, and a specific team was assigned responsibility for them. This team included a leader - who also acted as office manager of the laboratory administration and coordinator of the other teams that collaborated to develop the various elements of the library/database - as well as a couple of informaticians. This meticulous organization suggests that the managers of this facility require full commitment to its development and administration - demanding high M-B index scores unlike other team leaders whose attitudes were often lukewarm vis-à-vis such infrastructural obligations.

This initial scheme, however, did not develop as planned, owing perhaps to entangling factors. First, collecting natural products from individual laboratories presented a hindrance because these materials take years or even decades to extract, unlike commercially synthesized materials; being thus the object of researchers' attachment, it is difficult to get them released for public use (interviews, 25/5/2008, 30/6/2011). This aspect can be interpreted as a certain version of value oscillation: researchers officially understand the value of such a library, but they do not want to commit to it. A similar situation was found in the mouse genome database, where young researchers hesitated to submit their research outcomes to the database (Hine, 2006a).

Obtaining materials from retiring researchers before they closed their laboratories was slightly easier, but changing property rights trends, in which universities started to strengthen their control over the products of individual laboratories, are now a problem (interview, 29/5/2014). Thus, a sort of vicious cycle occurred: the failure to collect material enough to demonstrate the merit of such a library with its capacity for processing information in a high-throughput manner further diminished incentives for researchers to submit theirs.

The NPDepo's delay fostered stagnation in NPEdia's development. One of the expected functions of NPEdia, to serve as a full database for natural products, proved too feeble to work autonomously because of competition from rival databases for chemical compounds. Generally, in 
chemistry, SciFinder, by the American Chemical Society, has been one of the world's most comprehensive and authoritative sources of chemical compounds ${ }^{9}$. The chemists in the laboratory affirmed that SciFinder is sufficient for all parts of their work (interview, 14/8/2014). However, PubChem, released in 2004 by the National Center for Biotechnology Information (NCBI) as an open source database, focuses on the biological activities of small molecules and has recently gained popularity ${ }^{10}$. The informatician in charge of NPEdia explained that in NPEdia's earlier days, the idea of an open database specific to natural product compounds worthy of trial, such as PubChem, was still underdeveloped. However, the speed of data enrichment at PubChem surpassed that of NPEdia, making it extremely difficult for NPEdia to compete with its global rival (interview, 29/5/2014).

However, NPEdia could have retained its advantage if its catalogue function had been developed further. Natural products often occur in minuscule quantities in laboratory settings and are usually very hard to synthesize, which makes their production challenging for synthetic chemists - in some cases, global competition has developed among leading chemists to synthesize natural products first ${ }^{11}$.

This situation differs generally from that of chemical or genomic databases. For instance, the chemical databases mentioned above provide ample data related to methods of synthesis or about the vendors that sell such compounds. In the genomic database case, the recent development of commercial service companies has made it possible to quickly produce the necessary vectors from the genetic sequence information in such databases when a researcher asks for them. In other words, there are large networks of articles, laboratories, and vendors between the data in the database and the corresponding materials, which constitute a sub-layer of infrastructure, enabling the users of such databases to adapt the information to develop the materials they need (interviews, 22/5/2014; 6/6/2014; 22/8/2014) ${ }^{12}$.

In the case of natural products, this sub-layer has not developed fully, because of limited quantities and difficulty in reproduction. Thus, even if data about a particular compound are gained through the database, the only way to obtain the compound is to ask the laboratory to share the substance. According to a veteran natural product chemist, this is a complicated process because the laboratory may not exist any longer or because the laboratory has such a limited amount of the target compound that it cannot be shared. Even if, in rare cases, the compound might be synthesized and sold by vendors, its purity may be questionable, and further effort to refine the compound by reanalysing its real components may be required (interview, 22/8/2014).

NPDepo would thus be tremendously beneficial for users of such compounds because it would increase the ease of finding the target compound in the library, and the open protocol would simplify the procedure for obtaining material, eliminating negotiations with individual laboratories. NPEdia's full potential would be realized in this way as users could refer to the annotated information within the database and use it as a catalogue, as well.

However, this potential has not been realized thus far. Without NPDepo, NPEdia cannot compete with the existing databases, because its merit is sufficiently strong only with the support of NPDepo. Thus, the apparent powerlessness of NPEdia as a small, emerging database should not be understood solely as the problem of 'gateways' in terms of connecting isolated systems to larger ones (Edwards et al., 2007; Edwards et al., 2009), but also in the context of the data-material complex, where the material scarcity of natural products may have produced a unique set of datamaterial relations not seen in the wider genres of chemical or genetic databases.

This situation also relates to the relative invisibility of the problem of value oscillation here, in contrast with the preceding case of the chemical biology centre. Needless to say, as part of the centre, NPDepo/NPEdia would inevitably invite value oscillation for those who were obliged to commit themselves to infrastructural work. However, the more visible aspect of value oscillation lies at the sub-layer of the infrastructure - in the supporting network that enables the process of converting data in the database to its corresponding materials, under the guise of individual laboratories' reluctance to submit their materials 
to support the coming library as infrastructure. This contrasts with the case of the chemical biology centre, where the sway of the M-B index is much more easily observable as the centre scheme itself has more manifestly advanced.

\section{The Virtual Library as the Coming Knowledge Infrastructure?}

To observe the knowledge aspect of value oscillation more clearly in the emerging knowledge infrastructure of NPEdia-which has been realized only to a limited degree-let us briefly examine a supplementary case: the emerging virtual library of chemical compounds within the related scheme of RIKEN's drug discovery pipeline. This idea has been promoted by a research group related to the so-called $\mathrm{K}$ supercomputer in Kobe, West Japan, as part of a scheme to redevelop the city within a large biomedical complex after the 1995 earthquake (KBIC, 2012). K, from kei, meaning 'quadrillion' in Japanese, symbolizes the computation of 10 petaflops per second; this computer is intended to have the fastest computing speed in the world ${ }^{13}$. A number of projects related to this supercomputer are specifically concerned with computational drug discovery. There are at least two major plans: The first is to build a huge library of virtual chemical compounds, and the other to analyse ligand protein interaction using big data ${ }^{14}$.

The first plan relies on use of Archem - existing software originally designed for rapid analysis of the optimal paths for synthesizing the target compound - so as to produce large amounts of virtual compounds by reversing the process. The research group succeeded in producing five billion virtual chemical compounds (Ashida, 2010), an astronomical number compared to NPDepo's tens of thousands of compounds or to those of the drug companies, perhaps 10 million at best (interview, 12/5/2012). However, this does not include some of the complex cases of natural products that may often exhibit 3D structural complexity, such as chirality (interview, 2/9/2014). The purpose of this library is to examine the possible interaction between virtual compounds and the target proteins to predict the best-fit cases. The rising expectation that the supercomputer would handle huge computational loads made computer companies like Fujitsu eager to participate in this newly emerging field ${ }^{15}$.

However, these methods are not without problems. First, the issue of computational explosion remains in terms of how to balance between calculations based upon either Newtonian or quantum dynamics, and how (not) to calculate the influence of the molecules in the mediating substances, such as solutions or intracellular environments, existing between proteins and their ligands (interview, 12/8/2014). Most problematic, however, is the huge amount of noise. Just as in the past case of combinatorial chemistry, where the once-popular highthroughput production of new compounds has lost its glamour because of the huge nonsensical structures it produces (Barry, 2005; Borman, 2004), the virtual library must also sort significant structures from the huge amount of meaningless ones (interview, 2/9/2014). In fact, past reports indicate that existing calculations not done by $\mathrm{K}$ computers have produced a prediction success rate of less than $10 \%$ for proper protein-ligand binding (Kanai, 2012).

Thus, the second programme is designed to raise this success rate by enabling the computer to learn the pattern of such bindings using the existing databases on protein-ligand relations. In principle, this is performed similarly to the way a neural computer learns fingerprints or human faces. The success rate for prediction is expected to double from the traditional way of computing the molecular dynamics of these interactions (Kanai, 2012; Okuno, 2012).

In terms of value oscillation, these new radical features reveal intriguing problems not clearly seen in the NPEdia case. Although these programmes are still largely in development and are not ready for public use, their main researchers have enumerated hindrances to plan development, some of which I interpret as indicating value oscillation. For instance, they are uncertain whether they should continue maintenance work to promote the public use of this library as a resource centre after the present phase of system development. The laboratory head responsible for this scheme seems to have high M-B index scores, as he fully recognizes the importance of the infrastructural aspect of his role. His somewhat 
subtle value oscillation, then, may derive from his peculiar background, a hybrid of computing sciences and other disciplines, such as biology and astronomy. This background often makes him unsure of his position in each of these communities. At informational science meetings, he often finds his colleagues too excited over trivial software innovations; in our terms, he regards them having insufficient $M-B$ index scores for what they should do. However, in life science meetings, he feels that his computational approach is often merely subcontract work for the mainstream wet approaches, meaning that, paradoxically, he is dissatisfied with the way the biology community regards his work as infrastructural.

This means that his generally high M-B index is not sustainable all the time; occasionally, he feels that the essential work that he assigns to his staff - related to deleting all possible noise or the nonsensical chemical structures produced in the library - can be problematic when considering career development possibilities after such tedium (cf. Hine, 2008 for similar uncertainty) (interview, 2/8/2014).

The researcher in the second programme for the machine learning of ligand-protein binding, who seemed to have a very low M-B index score, shrewdly evaded the service aspect of work by entrusting it to a venture company that he established, exempting his laboratory from any further infrastructural work so that he could concentrate on the development of the new method (interview, 8/8/2014). Nevertheless, the value problem is unavoidable when his new method is applied in the real drug discovery context. The problem is how to gain support from chemists for synthesizing their computational predictions into the embodied compounds. The researcher admits that to synthesize the outcome of his very pragmatic machine learning with a process that is theoretically blackboxed would be considered by the synthetic chemists' community to be service work without scientific value - the M-B index score is close to zero here; thus, he asks for help with synthesis only from an old friend from high school. In the case of the virtual library, the researcher from the beginning plans to entrust the job to companies to avoid possible conflicts with scientists who do not want such subcontractlike duties (interviews, 8/8/2014; 2/9/2014).

These programmes are in a development stage wherein their innovative characteristics are spotlighted in public, but eventually, they will move into a maintenance - that is, infrastructural phase. The knowledge aspects of such infrastructural efforts entail the problem of data-material relations similar to the case of natural products above - namely, the problem of collaborating with synthetic chemists whose M-B index scores are often close to zero in terms of doing service work purely for such a virtual method. Likewise, in natural products, the chemists tend to be hesitant to become involved with the library plan, which is also interpretable as showing a low M-B index score.

This rather unstable relation between the knowledge and related material aspects in the form of non-collaboration by synthetic chemists shows the inherent instability of the in-process knowledge infrastructure. On this point, another specialist in the simulation of protein structures who participates in the $\mathrm{K}$ computer programme pointed out the inevitable duality of the infrastructural and innovative aspects of computer technology and the difficulty of balancing them. He noted that computer technology is now widely distributed even in the basic tools of the structural analysis of proteins - namely, in X-rays and NMR spectroscopy - where complex signals are analysed with the help of computerized data processing. Thus, he underscored that even in his laboratory, the aspects of the cutting edge of innovation and infrastructural work exist side by side. He emphasized that the latter should be treated carefully in such ways as developing and fine-tuning the software needed for such simulations, which is ordinarily seen as infrastructural work that does not produce appreciable credentials; thus, careful persuasion is needed to enlist members of the laboratory for such work (interview, 12/8/2014).

\section{Discussion}

The main claim of this research is that value oscillation is intrinsic to consolidating and maintaining infrastructures of any type. The problem, then, 
is how it takes shape and is dealt with according to different degrees of infrastructure consolidation within multiple layers. In fact, a series of preceding discussions have taken place on the perpetual tension or contradiction between the approaches of biology and computer science, often dubbed 'wet' and 'dry' approaches in the research on genomic sciences. For instance, García-Sancho (2012) traces the relation between genetic/protein science and sequence technique as a constant swinging between antagonism and accommodation. In more detailed microscopic studies, Lewis and Bartlett (2013) discuss the problem of bio-informatician identity, which sways between scientists pursuing new knowledge and technicians supporting the jobs of wet biologists. In preceding studies more on knowledge-infrastructural aspects of laboratory work, Star and Ruhleder (1996: 126) refer to a primordial case of value oscillation that they call 'tool building and the reward structure' in their case study of the gene-sequencing network. In relation to the mouse-based genetic database, Hine (2006a) details various potential conflicts and their avoidance in cases similar to the institutional separation between biologists and the resource centre, while her analysis of systematics (Hine, 2008) delineates the value oscillative aspects in more detail.

Compared to these preceding examples, the two cases in this paper appear to be situated on a more complex institutional ladder - one in the chemical biology centre, the other in the $\mathrm{K}$ computer project, and both within RIKEN's wider programme. These two are also situated in the wider context of a more established knowledge infrastructure: the databases of chemical and genomic information.

Hence, the phenomenon of value oscillation is most visible at the rather established level of the centre, whose purpose from the beginning has been torn between the goals of an infrastructural service centre and those of a centre for innovating research; the M-B index appeared to be literally fluctuating, as observed in both the leader's and researchers' discourses and action in various contexts. In contrast, the subsequent cases of NPEdia and the virtual library demonstrate a more complex picture owing to their being embedded in multiple layers of both organizations and other databases while falling short of establishing a proper level of autonomy. Hence in the case of NPEdia, the value oscillation is spotted in the sub-layer that supports this database, while in the case of the virtual library, diverse strategies were observed for avoiding a double-bind situation: that is, the shrewd avoidance of a further commitment to maintenance and dissatisfaction with the indeterminate character of the concerned researcher's role in terms of infrastructure development. Thus, compared to the preceding arguments that emphasized a rather black-andwhite image of contradictory values, these cases exhibit a more subtle and layered embodiment of value oscillation, as well as diverse ways the practitioners deal with it.

\section{Conclusion}

I have argued here that current studies of infrastructure have suffered from historical amnesia lacking critical dialogue with the preceding Marxist discussions on Infrastructure in terms of the genealogy of concepts. I have pointed out that an opportunity has been missed for theoretical dialogue in relation to at least three major questions, the last of which is highlighted in this paper: the pivotal importance of the Marxist operation of inverting the unseen value of Infrastructure, which has been occulted by the shadow of Superstructure - the operation represented by the phrase 'turning Hegel on his head'. I claimed that this operation is intrinsically isomorphic with Bowker's 'infrastructural inversion', now regarded as pivotal in contemporary research on this topic. Behind the need for this operation lies the recognition that the concept of infrastructure is an oxymoron, imbued with contradictory meaning - that is, infrastructure is endowed with power while it is simultaneously inferior to the surface value.

'Value oscillation' is the term used to describe this double-bind situation whereby practitioners hang in indeterminacy between opposite vectors, and the $M-B$ index is the tool used to visualize these oscillating values. Two cases of such value oscillation were taken from the drug discovery infrastructure building in Japan where the knowledge of drugs is uniquely entangled with the physical material in a complex, layered manner. 
To elucidate further implications of my approach here, we must note that the recent rise in concern with the infrastructure in the STS community derives not only from growing academic interest in such individual cases as the computer network or energy infrastructure but also from increasing attention within the research community to the more structuralized, longue duree elements of socio-technical development rather than to the early and rapidly changing aspects of technoscientic transformation. These renewed intellectual concerns can be observed in such diverse expressions as a reference to the 'cold' situation (Rip, 2010), the 'obduracy' of urban technology (Hommels, 2005) or even 'the shock of the old' (with regard to technologies) (Edgerton, 2006; cf. Fukushima, 2015).

Two points can be drawn from this observation. The first is the merit of talking about infrastructure vis-à-vis the related concepts cited above. Conceptually, infrastructure leads us to focus on the dual aspects of a) its power to exert influence upon that which hinges upon it and b) its invisibility. In this article, I have pointed out the diverse strategies produced by value oscillation, ranging from devotion to shadow work - that is, efforts to raise the status of what is invisible - to the minimal commitment devoted to maintaining and repairing infrastructure. Beyond the microsociological examples presented in this paper, larger-scale and more historical consequences of such value oscillation will be similarly important in further examining the longitudinal dynamics of the infrastructure at large - represented, say, by such instances as the recent issue of roads and bridges in decay, owing to politicians' general lack of interest in their proper maintenance (Nemoto, 2011).

The second point is the yet unexamined relationship, in this era wherein STS scholarship highlights the rapidly changing, unstable network of humans and nonhumans, between current concepts of infrastructure and the century-old use of 'structure' in the social sciences. Though not detailed above, the concept of infra-'structure' is not only comparable to its Marxist counterpart but it also partakes of the larger genealogy that has taken its intellectual inspiration from the concept of structure found in structural functional sociology or even structuralism.

Take, for instance, my formulation of value oscillation vis-à-vis the dual aspects of infrastructure - namely, its power to exert influence and its invisibility. If we slightly modify this idea to consider the contrast between the various forms of our 'existence' in terms of l'engagement, and the power of invisible structure - whatever that means - to exert an implicit influence upon this existence, this contrast dimly echoes a well-known historical controversy: Sartre's revised concept of existentialism, somewhat modified by his conversion to historical materialism (Sartre, 1976), versus Levi-Strauss's (1966) fatal criticism in which he highlighted the determining power of classification and taxonomy as the invisible structure that regulates our very understanding of history. In fact, the missing link with Marxism which I have highlighted in this paper is only the tip of the iceberg in terms of possible linkages. Godelier (2011; Godelier et al. 1978), for instance, can also be regarded as a concrete embodiment of the confluence of both Marxism and structuralism, which later leads to the thesis of 'classification as infrastructure' that is foundational for the current discussion of knowledge infrastructure.

My emphasis on the resurgence of the intellectual concern with the concept of structure lurking in infrastructural studies, however, does not deny the novelty of the later approach vis-a-vis the earlier. Compared to the more traditional ways of dealing with structure - either as an invisible mental structure or as the social structure, mostly as it relates to humans - current infrastructure studies provide a series of fresh perspectives on the socio-technical complex. Its workings can be more closely observed through modern than through more traditional ways, such as with case studies on roads and databases, which were unanticipated in the past. This is why infrastructure studies, even if they share a concern with past problematics in the social sciences, do not merely repeat the past (cf. Marx, 1994) but may be considered as more finely-tuned re-examinations of persisting controversies from the past, generated by the historical genealogy of concepts through which we see the world. 


\section{Notes}

1 The earliest version of this formula appeared in the posthumous publication of a draft called Grundrisse der Kritik der politischen Ökonomi (Outline of the Critique of Political Economy), written around 1857-58.

2 The labour process theory is a possible candidate for bridging these two research traditions (Braverman, 1974; Nakaoka, 1971; Knights \& Willmott, 1990; Sturdy et al., 1992). Vann and Bowker (2006), somewhat exceptionally, reflect this line of concern by focusing on the production side of e-science, emphasising the role of funding agencies, thus recalling classical arguments on the role of the capitalist class.

3 This nuance can be contrasted with technological regimes, highlighting the total visibility of the phenomena (Rip, 1995; Rip \& Kemp, 1998, followed by many).

4 Included in this category are requests for more attention to neglected aspects of laboratory technicians and technical workers at large (Barley \& Bechki, 1994; Barley \& Orr, 1997) as well as the Burri's (2008) analysis of radiologists' strategy in terms of cultural capital and boundary work.

5 This paper draws on data from various phases of my ethnographic research in the antibiotic laboratory and chemical biology (2007-2010), the Protein 3000 Project (2010-2013), and drug discovery infrastructure (2013-), which are all related to RIKEN. Interviews were conducted with researchers in various genres on the topic of this theme, both inside and outside the institute.

6 RIKEN's recent programme can be seen at http://www.riken.jp/dmp/english/index_en.html (accessed 22/8/2014)

7 In 2007, ten teams covered the following themes:

1. Streptomyces

2. Genetic analysis of secondary metabolites

3. Fractions

4. Chemical library

5. Compound array

6. Protein analysis

7. Cancer related issues

8. Cell cycles

9. Transcription

10. Chemical compounds at large $2-5$ and 10 are largely for infrastructural works

8 See Parry (2004) for the history of the U.S. Natural Products Repository of the National Cancer Institute. Compared to this global scheme, NPDepo is straightforwardly intended for public use for both research and drug discovery.

9 SciFinder's official home page is http://www.cas.org/products/scifinder (accessed 22/8/2014). For its history since 1995, see Chemical Abstract Service (2007).

10 PubChem, launched in 2004 by the National Center for Biotechnology Information (NCBI), is a freeaccess database focusing on the biological activities of small molecules. It has experienced serious friction with SciFinder (Marris, 2005). https://pubchem.ncbi.nIm.nih.gov/about.html (accessed 22/8/2014).

11 The global competition of synthesizing taxol, an anti-cancer material extracted from Pacific yew, is such a case. In 1993, R. Holton succeeded in its total synthesis. Despite millions of dollars spent, the resulting method, which has more than 40 steps, has not been used for actual drug production (Sato, 2007: 78-86).

12 The case presented here highlights the limit of Parry's (2004) claim concerning the growing use of what she calls the dominance of ex-situ data mining. In addition, this line partially refutes Elvebakk's (2006) claim that chemistry has largely become a matter of examining information.

13 http://www.aics.riken.jp/en/k-computer/about/ (accessed 20/8/ 2014).

14 http://www.mext.go.jp/b_menu/houdou/24/09/__icsFiles/afieldfile/2012/09/04/1325265_1_1.pdf (accessed 20/8/2014). 
15 Thus, the University of Tokyo, Fujitsu, and the Kowa Company announced the discovery of an anti-cancer drug candidate through computer-based virtual design. http://www.rcast.u-tokyo.ac.jp/research/ report/2014/140807PR.pdf (accessed 18/8/2014).

\section{Acknowledgements}

I thank all the interviewees in RIKEN and elsewhere for kindly answering my questions. I thank Geof Bowker for introducing me to the world of knowledge infrastructure studies; Antti Silvast and two anonymous reviewers for their constructing comments. This research was conducted with the support of grantsin-aid for scientific research from the Japan Society for the Promotion of Science, under Grant 26350359 (2014-2016).

\section{References}

Althusser L \& Balibar É (1970) Reading Capital. London: New Left Review.

Anderson P (1976) Considerations on Western Marxism. London: New Left Books.

Ashida J (2010) Sharing Information Using ARChem. CICSJ Bulletin 28(1): 15-16. (in Japanese)

Barley S \& Bechky B (1994) In the Backrooms of Science: The Work of Technicians in Science Labs. Work and Occupations 21(1): 85-126.

Barley S \& Orr J (eds) (1997) Between Craft and Science: Technical Work in U.S. Settings. Ithaca, NY: ILR Press.

Barry A (2005) Pharmaceutical Matters: The Invention of Informed Materials. Theory, Culture \& Society 22(1):51-69.

Bartfai T \& Lees G (2006) Drug Discovery: From Bedside to Wall Street. Amsterdam: Elsevier Academic Press.

Bataille G (1988) The Accursed Share: An Essay on General Economy. Cambridge, Mass.: Zone Books.

Bateson G (1972) Steps to an Ecology of Mind: Collected Essays in Anthropology, Psychiatry, Evolution, and Epistemology. Chicago: University of Chicago Press.

Baudrillard J (1981) For a Critique of the Political Economy of the Sign. Candor, NY: Telos Press.

Bensaude-Vincent B \& Stengers I (1996) A History of Chemistry. Cambridge Mass.: Harvard University Press.

Borman S (2004) Rescuing Combichem: Diversity-oriented Synthesis Aims to Pick Up Where Traditional Combinatorial Chemistry Left Off. C\&EN: Science \& Technology 82(40): 32-40

Bowker G (1994) Information Mythology. The World of/as Information. In: Bud-Frierman L (ed) Information Acumen: The Understanding and Use of Knowledge in Modern Business. London: Routledge, 231-247.

Bowker G \& Star S (1999) Sorting Things Out: Classification and Its Consequences. Cambridge, Mass.: MIT Press.

Bowker G, Baker K, Millerand F \& Ribes D (2010) Towards Information Infrastructure Studies: Ways of Knowing in a Networked Environment. In: J Hunsinger, J Allen \& L Klastrup (eds) International Handbook of Internet Research. Drotrecht: Springer, 97-117.

Braverman H (1974) Labor and Monopoly Capital: The Degradation of Work in the Twentieth Century. New York: Monthly Review Press.

Burri R (2008) Doing Distinctions: Boundary Work and Symbolic Capital in Radiology. Social Studies of Science 38(1): 35-62.

Carse A (2012) Nature as Infrastructure: Making and Managing the Panama Canal Watershed. Social Studies of Science 42(2): 539-563. 
Chemical Abstract Service (2007) A National Historic Chemical Landmark. Available at: http://www.acs.org/ content/dam/acsorg/education/whatischemistry/landmarks/cas/chemical-abstracts-service-commemorative-booklet.pdf (accessed 28.8.2014).

Clarke A \& Fujimura J (eds) (1992) The Right Tools for the Job: At Work in Twentieth-Century Life Sciences. Princeton: Princeton University Press.

Edgerton D (2006) The Shock of the Old: Technology and Global History Since 1900. Oxford: Oxford University Press

Edwards P, Jackson S, Bowker G \& Knobel C (2007) Understanding Infrastructure: Dynamics Tensions and Design. NSF Office of Cyberinfrastructure. Available at: http://cohesion.rice.edu/Conferences/Hewlett/ emplibrary/UI_Final_Report.pdf (accessed 10.6.2014).

Edwards P, Bowker G, Jackson S \&Williams R (2009) Introduction: An Agenda for Infrastructure Studies. Journal of the Association for Information Systems 10(5): 364-374.

Edwards P, Mayernik M, Batcheller A, Bowker G \& Borgman C (2011) Science Friction: Data, Metadata, and Collaboration. Social Studies of Science 41(5): 667-690.

Edwards P, Jackson S, Chalmers M, Bowker G, Borgman C, Ribes D, Burton M \& Calvert S (2013) Knowledge Infrastructures: Intellectual Frameworks and Research Challenges. Available at: http://knowledgeinfrastructures.org/ (accessed 20.4.2014).

Elvebakk B (2006) Network of Objects: Practical Preconditions for Electric Communication. In: Hine C (ed) New Infrastructures for Knowledge Production: Understanding E-Science. Hershey: Information Science Pub.,120-142.

Endo A (2006) The Discovery of a New Drug Statin: Challenging Cholesterol. Tokyo: Iwanami-shoten. (in Japanese)

Epstein R (2006) Overdose: How Excessive Government Regulation Stifles Pharmaceutical Innovation. New Haven: Yale University Press.

Epstein S (2007) Inclusion: The Politics of Difference in Medical Research. Chicago: University of Chicago Press.

Fujimura J (1996) Crafting Science: A Sociohistory of the Quest for the Genetics of Cancer. Cambridge Mass.: Harvard University Press.

Fukushima M (2005) On Small Devices of Thought: Concepts, Etymology and the Problem of Translation. In: Latour B \& Weibel P (eds) Making Things Public: Atmosphere of Democracy. Cambridge Mass.: The MIT Press, 58-63.

Fukushima M (2013) Between the Laboratory and the Policy Process: Research Scientific Community and Administration in Japans Chemical Biology. East Asian Science Technology and Society 7: 7-33.

Fukushima M (2015) Resilience in Scientific Research: Understanding How Natural Product Research Rebounded in an Adverse Situation. Science as Culture. (First on line).

Fukushima M (2016) Constructing Failure in Big Biology: The Socio-technical Anatomy of Japan's Protein 3000 Project. Social Studies of Science 46(1): 7-33.

García-Sancho M (2012) Biology Computing and the History of Molecular Sequencing: From Proteins to DNA 1945-2000. Basingstoke: Palgrave Macmillan.

Gaudillière JP \& Löwy I (eds) (1998) The Invisible Industrialist: Manufactures and the Production of Scientific Knowledge. London: Palgrave Macmillan.

Geertz C (1973) The Interpretation of Cultures. New York: Basic Books.

Godelier M, Bloch M, Claessen H, Gilmore D, Pi-Sunyer O \& Tagányi Z (1978) Infrastructures, Societies and History [and Comments]. Current Anthropology 19(4): 763-771. 
Godelier M (2011) The Mental and the Material: Thought Economy and Society. London: Verso.

Hayek F (1978) New Studies in Philosophy, Politics, Economics and the History of Ideas. London: Routledge \& Kegan Paul.

Heidegger M (1968) What is a Thing? Chicago: H. Regnery.

Hine C (2006a) Databases as Scientific Instruments and Their Role in the Ordering of Scientific Work. Social Studies of Science 36 (2): 269-298.

Hine C (ed) (2006b) New Infrastructures for Knowledge Production: Understanding E-Science. Hershey: Information Science Pub.

Hine C (2008) Systematics as Cyberscience: Computers Change and Continuity in Science. Cambridge Mass.: the MIT Press.

Hommels A (2005) Unbuilding Cities: Obduracy in Urban Sociotechnical Change. Cambridge Mass.: the MIT Press.

Howard D \& Klare K (eds) (1972) The Unknown Dimension: European Marxism since Lenin. London: Basic Books.

Hughes T (1983) Networks of Power: Electrification in Western Society 1880-1930. Baltimore: Johns Hopkins University Press.

Joerges B \& Shinn T (2001) A Fresh Look at Instrumentation: An Introduction. In: Joerges B \& Shinn T (eds) Instrumentation between Science, State and Industry. Dortrecht: Kluwer Academic Publishers, 1-13.

Kanai C (2012) In Silico Screening Using Chemical Genomic Information. CICSJ Bulletin 30(4): 69-72. (in Japanese)

Karatani K (2014) The Structure of World History: From Modes of Production to Modes of Exchange. Durham North, Carolina: Duke University Press.

KBIC (2012) Kobe Biomedical Innovation Cluster. Available at: http://www.city.kobe.lg.jp/information/ project/iryo/img/iryou.pdf (accessed 20.8.2014).

Keating P \& Cambrosio A (2003) Biomedical Platforms: Realigning the Normal and the Pathological in LateTwentieth-Century Medicine. Cambridge Mass.: The MIT Press.

Keating P \& Cambrosio A (2012) Cancer on Trial: Oncology as a New Style of Practice. Chicago: The University of Chicago Press.

Knights D \&Willmott H (eds) (1990) Labour Process Theory. London: Macmillan.

Kubinyi H (2003) Drug Research: Myths Hype and Reality. Nature Reviews Drug Discovery 2: 665-668.

Latour B (2005) From Realpolitik to Dingpolitik or How to Make Things Public. In: Latour B \& Weibel P (eds) Making Things Public: Atmosphere of Democracy. Cambridge Mass.: the MIT Press, 14-41.

Lévi-Strauss C (1966) The Savage Mind. Chicago: Chicago University Press.

Lewis J \& Bartlett A (2013) Inscribing a Discipline: Tensions in the Field of Bioinformatics. New Genetics and Society 32(3): 243-263.

Lichtheim G (1971) From Marx to Hegel. New York: Herder and Herder.

Luhmann N (1980) Gesellschaftsstruktur und Semantik : Studien zur Wissenssoziologie der modernen Gesellschaft. Bd.1. Frankfurt a. M.: Suhrkamp.

Marris E (2005) Chemical Reaction. Nature 437(October): 807-809.

Marx K (1973) Grundrisse: Foundations of the Critique of Political Economy (rough draft). Harmondsworth: Penguin Books.

Marx K (1976-1981) Capital: A Critique of Political Economy. London: Penguin Books in association with New Left Review. 
Marx K (1994) The Eighteenth Brumaire of Louis Bonaparte. New York: International Publishers.

Mazzucato M (2013) The Entrepreneurial State: Debunking Public vs. Private Sector Myths. New York: Anthem Press.

McLellan D (1979) Marxism after Marx: An Introduction. London: Macmillan.

Mody C (2011) Instrumental Community: Probe Microscopy and the Path to Nanotechnology. Cambridge Mass.: the MIT Press.

Nakaoka T (1971) The Philosophy of Factory. Tokyo: Heibonsha. (in Japanese).

Nemoto Y (2011) Decaying Infrastructure: Another Crisis that Creeps Up to Us. Tokyo: Nihonkeizai Shinbunsha. (in Japanese)

Newman D \& Cragg G (2007) Natural Products as Sources of New Drugs over the Last 25 Years. Journal of Natural Products 70(3): 461-477.

Okuno K (2012) Chemo-genomics: Form Genome to Chemical Space. CICSJ Bulletin 30(4): 60. (in Japanese).

Parry B (2004) Trading the Genome: Investigating the Commodification of Bio-Information. Princeton: Princeton University Press.

Petryna A (2009) When Experiments Travel: Clinical Trials and the Global Search for Human Subjects. Princeton: Princeton University Press.

Polanyi K (1944) The Great Transformation. New York: Farrar \& Rinehart.

RIKEN (2005). 88 Years of RIKEN's History (in Japanese). Available at: http://www.riken.go.jp/r-world/info/ release/riken88/book/ (accessed 22.1.2007).

Rip A (1995) Introduction of New Technology: Making Use of Recent Insights from Sociology and Economics of Technology. Technology Analysis and Strategic Management 7: 417-31.

Rip A (2010) Processes of Entanglement. In: Akrich M, Barthe Y, Muniesa F \& Mustar P (eds) Débordements: Mélanges offerts à Michel Callon. Paris: Presses des Mines, 381-392.

Rip A \& Kemp R (1998) Technological Change. In: Rayner S \& Malone E (eds) Human Choice and Climate Change. Columbus, Ohio: Battelle Press, 327-399.

Rheinberger HJ (1997) Toward a History of Epistemic Things: Synthesizing Proteins in the Test Tube. Stanford, CA: Stanford University Press.

Rydzewski R (2008) Real World Drug Discovery: A Chemists Guide to Biotech and Pharmaceutical Research. Amsterdam: Elsevier.

Sahlins M (1972) Stone Age Economics. Chicago: Aldine.

Sartre JP (1976) Critique of Dialectical Reason. London: New Left Books.

Sato K (2007) Welcome to a Museum of Organic Chemistry. Tokyo: Gijutsu-hyoronsha. (in Japanese).

Shiozawa Y (2002) The Legacy of Marx: From Althusser to Complexity. Tokyo: Fujiwara-Shoten. (in Japanese)

Star S (1999) The Ethnography of Infrastructure. American Behavioral Scientist 43(3): 377-391.

Star S \& Bowker G (2002) How to Infrastructure? In: Lievrouw L \& Livingstone S (eds) The Handbook of New Media: Social Shaping and Consequences of ICTs. London: Sage Publications, 151-162.

Star S \& Ruhleder K (1996) Steps toward an Ecology of Infrastructure: Borderlands of Design and Access for Large Information Spaces. Information Systems Research 7(1): 111-134.

Sturdy A, Knights D \& Willmott H (eds) (1992) Skill and Consent: Contemporary Studies in the Labour Process. London: Routledge.

Ueno A (2008) Study on the Organizational Knowledge of Research Laboratories with Long Histories. Discussion Paper No.50, National Institute of Science and Technology Policy (NISTEP): 1-94. (in Japanese) 
Vann K \& Bowker G (2006) Interest in Production: On the Configuration of Technology-Bearing Labors for Epistemic IT. In: Hine C (ed) (2006) New Infrastructures for Knowledge Production: Understanding E-Science. Hershey: Information Science Pub., 71-97.

Vertesi J (2014) Seamful Spaces: Heterogeneous Infrastructures in Interaction. Science Technology \& Human Values 39(2): 264-284.

Weick K \& Westley F (1999) Organizational Learning: Affirming an Oxymoron. In: Clegg S, Hardy C \& Nord W (eds) Managing Organizations: Current Issues. London: Sage Publications, 440-458.

Wikstrom M (2007) Chemical Biology in the USA. Swedish Institute for Growth Policy Studies. Available at: http://www.vinnova.se/upload/dokument/Verksamhet/Bioteknik/Rapporter_Life_Science/Chemical\%20 Biology.pdf (accessed 21.1.2012).

Williams R (1976) Keywords: A Vocabulary of Culture and Society. London: Fontana/Croom Helm. 